\title{
SISTEMAS VINCULARES VITIMIZADO E CIDADÃO: UMA PROPOSTA SOCIONÔMICA
}

\author{
Daniel C. R. Gulassa' 1 iD
}

\begin{abstract}
RESUMO
Neste relato de experiência como terapeuta em programa governamental na periferia da cidade de São Paulo, o objetivo foi compreender, com enfoque na metodologia socionômica, como técnicos e usuários de um serviço assistencial lidaram com seus desafios do dia a dia no contexto comunitário. Foram identificadas duas sociodinâmicas dos papéis observados: o denominado Sistema Vincular Vitimizado (SVV), que atribui grande parte da responsabilidade dos acontecimentos a terceiros, envolvendo expectativa, culpa, busca de bodes expiatórios e consequente exclusão social; e o denominado Sistema Vincular Cidadão (SVC), que atribui corresponsabilidade, envolvendo diálogo e negociação na procura de soluções viáveis e gerando inclusão social. O SVV se mostrou menos eficiente na superação de desafios e a intervenção socionômica facilitou uma transição do SVV para o SVC.
\end{abstract}

PALAVRAS-CHAVE: Socionomia; Vitimização; Cidadania; Inclusão social; Exclusão social.

\section{VICTIMIZED AND CITIZEN BOND SYSTEMS: A SOCIONOMIC PROPOSAL}

\begin{abstract}
In this experience report as a therapist in a governmental program on the outskirts of the city of São Paulo, the goal was to understand, focusing on the socionomic methodology, how technicians and users of assistance service managed their day-to-day challenges in the community context. Two socio-dynamics were identified in the observed roles: the first one, named Victimized Bond System (VBS), assumes that most of the responsibility of the events belongs to third parties, involving expectation, guilt, scapegoating and consequent social exclusion; and the so-called Citizen Bond System (CBS), which attributes co-responsibility, involving dialogue and negotiation in search of viable solutions and generating social inclusion. VBS was proved less efficient in overcoming challenges and the socionomic intervention facilitated a transition from VBS to CBS.
\end{abstract}

KEYWORDS: Socionomy; Victimization; Citizenship; Social inclusion; Social exclusion.

\section{SISTEMAS VINCULARES VICTIMIZADO Y CIUDADANO: UNA PROPUESTA SOCIONÓMICA}

\section{RESUMEN}

En este informe de experiencia como terapeuta en programa gubernamental en las afueras de la ciudad de São Paulo, el objetivo fue comprender, enfocándose em la metodologia socionómica, cómo técnicos y usuarios del servicio de asistencia afrontaban sus desafíos cotidianos em el contexto comunitario. Se identificaron dos sociodinámicas de los roles observados: el llamado Sistema de Enlace Victimizado (SEV), que atribuye gran parte de la responsabilidad de los eventos a terceros, lo que implica expectativas, culpa, chivos expiatorios y la consiguiente exclusión social; y el llamado Sistema de Enlace Ciudadano (SEC), que atribuye la corresponsabilidad, lo que implica el diálogo y la negociación em la búsqueda de soluciones viables y generando inclusión social. El SVV fue menos eficiente para superar los desafíos y la intervención socionómica facilitó la transición del SEV al SEC.

PALABRAS CLAVE: Socionomía; Victimización; Ciudadanía; Inclusión social; Exclusión social.

1.Sociedade de Psicodrama de São Paulo - São Paulo (SP), Brasil

*Autor correspondente: danielgulassa@hotmail.com

Editora de seção: Marcia Almeida Batista

Recebido: 26 Nov 2021 | Aceito: 20 Mar 2021 


\section{INTRODUÇÃO}

Esta produção escrita reflete a experiência de trabalho terapêutico e socioeducacional como psicólogo técnico em programa governamental de uma região periférica da cidade de São Paulo. Os objetivos do programa foram, através da rede de proteção socioassistencial, identificar necessidades, intervir em famílias com altíssima vulnerabilidade social e contribuir para que moradores desenvolvessem cidadania com participação nos projetos da comunidade. A perspectiva teóricometodológica utilizada foi a socionomia de J. Moreno, com ênfase na teoria de papéis. Ademais, para realizar uma leitura sociodinâmica do modo como se lida com desafios em situações difíceis ou inesperadas, foram consideradas diferentes instâncias do trabalho - membros da comunidade, técnicos, incubadora (instituição contratada para realizar o programa) e governo - , com as quais este autor teve contato como técnico.

Este artigo também faz parte do cumprimento das exigências para a formação como psicodramatista didata supervisor pela Sociedade de Psicodrama de São Paulo (SOPSP).

$\mathrm{O}$ atendimento descrito abrangeu uma região composta por quatro bairros, situados nos arredores de uma favela na periferia da capital paulista. Como único técnico e psicólogo oferecendo atendimento público gratuito, mobilizou-se uma demanda de psicologia e psicoterapia comunitária, absorvida principalmente através de atendimentos grupais. O trabalho mencionado durou seis meses, entre outubro de 2004 e abril de 2005, desde a inserção deste profissional em substituição a outro, até a finalização do programa na região.

O status nascendi desta produção escrita teve início quando os técnicos desse programa souberam de sua extinção nas áreas atendidas, logo após a mudança do governo. A interrupção do serviço foi manejada com despreparo, desorganização e desinformação por parte dos funcionários públicos, líderes da incubadora e técnicos. Nestes, evidenciou-se a sensação de impotência, injustiça e frustração, manifesta em frases de resignação como: "o pobre é sempre abandonado nesse país", "esse Brasil não vai mudar nunca", numa postura bastante semelhante àquela que se dizia tentar alterar nos moradores das comunidades. Também foi identificada outra postura frente à situação - menos dramática e mais resiliente — que visava à adaptação à nova realidade, ao aprendizado construtivo a partir da situação vivida e à preservação dos ganhos obtidos até então, mais associada a características cidadãs.

Para a análise apresentada, o autor considerou três momentos: o da atuação como técnico, durante o andamento do programa; como técnico/pesquisador durante sua finalização; e como pesquisador/observador, a partir de um distanciamento temporal da experiência em si.

O recorte estabelecido para a análise dos dados coletados teve como critério tudo aquilo que pareceu aproximar ou distanciar os sujeitos envolvidos do exercício da cidadania.

O distanciamento temporal entre os eventos descritos e esta elaboração favoreceu uma visão distanciada deles e possibilitou o reconhecimento de que as duas posturas aqui discriminadas não são restritas apenas à época e ao local em que foram identificadas originalmente. Os manuscritos deste trabalho foram recuperados em 2020, momento em que foi possível cotejar os desafios emergidos na comunidade periférica de São Paulo, em 2004/2005, com os desafios colocados pela pandemia do Covid-19 e seu manejo por parte da comunidade global em 2020, identificando entre eles características comuns. Em ambos, duas formas de conexão entre os atores envolvidos foram constatadas, e serão aqui conceituadas, respectivamente, como Sistema Vincular Vitimizado (SVV) e Sistema Vincular Cidadão (SVC). A primeira envolveu principalmente uma postura e compreensão dos desafios vividos em comunidade que pressupunha atores com característica binária de valores (bem/mal) e potência (culpado/inocente) e que, a partir da combinação das mesmas, procedia de modo a eleger algozes, vítimas e salvadores; a segunda, envolveu uma postura e compreensão dos desafios pautadas na interação de atores com variadas nuances de forças que, com seus potenciais e limites reconhecidos e na combinação dos mesmos, podiam atuar como coconstrutores, buscando superação viável do(s) problema(s) e aprendizado construtivo. Como consequência da permanência em cada uma das posturas, no SVV identificaram-se sensações de expectativa, decepção e sofrimento, e no SVC, esperança, senso de realização e empoderamento. Embora a comparação permita reconhecer a amplitude desse recorte e sua pertinência no momento atual, o objetivo aqui não é discorrer sobre a pandemia de 2020 - é possível encontrar nas mídias exemplos dos dois tipos de sistemas vinculares descritos -, mas sim descrever e analisar, a partir da atuação como 
terapeuta na periferia de São Paulo em 2004/2005, as intervenções socionômicas que tinham como objetivo promover uma relação mais saudável com os desafios, ou até sua superação — na transição de SVV para SVC.

Esta produção alterou registros para garantir confidencialidade das pessoas e grupos envolvidos e está em consonância com a Resolução CNS 510/2016 (cap. 1, art. 2, par. XV das normas de pesquisas nas áreas de ciências sociais e humanas envolvendo seres humanos).

\section{Conceitos Teóricos}

A cidadania é um conceito historicamente construído com lutas e conquistas, que parte da compreensão dos membros de uma sociedade como participantes ativos, com direitos e deveres, da vida em comunidade nos seus mais variados aspectos (político, social, econômico) até uma compreensão mais ampla e atual que inclui o processo da coexistência equilibrada dos diferentes grupos e culturas (Porto, 2018). Cidadania é ainda saúde relacional (inter e intrapsíquica), é conscientização de si como parte de um contexto, é responsabilizar-se por sua saúde, recursos próprios e públicos, e por seu livre-arbítrio (Zampieri, 2005). O papel de cidadão está associado a um cacho de papéis saudável (Gulassa, 2018) e à inclusão social, uma atitude de desenvolvimento, pertencimento, empoderamento, emancipação social, política e econômica, de perceber as coisas, a si e ao outro, com suas características idiossincráticas reconhecidas e valorizadas (Camargo, 2017). A exclusão social, por sua vez, é um processo que remete à discriminação, não aceitação, isolamento e vulnerabilidade de parcelas da população, expresso por obstáculos sociais, políticos e econômicos que as impedem da participação plena na sociedade (Fichtner, 2017).

Quanto ao conceito de vítima, este pode ser compreendido de inúmeras formas. A Organização das Nações Unidas (ONU) define vítima como as pessoas que tenham sofrido danos, sejam físicos, mentais, emocionais ou financeiros, devido às ações ou omissões que violem as leis vigentes nos Estados-membros (Morotti, 2015). Existe ainda uma área do conhecimento destinada ao estudo do comportamento da vítima — a vitimologia — e que estuda sua diferenciação, por exemplo, por graus de culpabilidade ("inocente", "culpabilidade menor", "tão culpada quanto" ou "mais culpada” que o infrator). Entende-se então que podem existir níveis e formas de participação da vítima que inclusive reiteram a sua condição (Mello \& Lira, 2019). Existem também culturas grupais que tendem a sustentar alguém no papel de vítima. Nestas, qualquer um de seus membros estará sujeito a encarnar ou ser visto como bode expiatório, que, independentemente de ser do tipo negativo ou positivo, é um mau prognóstico para a sobrevivência do indivíduo. O bode expiatório é um fenômeno universal e remete a um antigo ritual judaico com dois bodes selecionados — um bode, simbolicamente investido de qualidades "boas", é dedicado a Deus e sacrificado como uma oferenda no templo; o outro, dedicado ao anjo caído e carregado com os pecados do grupo, é abandonado em exílio no deserto (Yalon \& Leszcz, 2006). A vítima pode ainda ser vista como um dos vértices de uma relação triangular que a sustenta, juntamente com os papéis de perseguidor e salvador - comumente representados nos contos de fadas -, compreensão da qual a análise transacional partiu para explicar e intervir principalmente nas relações familiares. Trata-se de uma visão de mundo em que são incutidos no indivíduo três papéis com scripts estereotipados (de perseguidor, salvador e vítima). O indivíduo encarna um papel principal, mas transita por dois ou mais, afinal, a internalização dessa forma de se relacionar torna ele mesmo o produtor dos aspectos de sua versão imaginada da relação triangular (Karpman, 2019). No contexto comunitário, Barreto (2008) menciona a triangulação vitimizadora, e alerta para o risco de o terapeuta comunitário cair em um papel de salvador e eleger alguém como perseguidor. Ele diz, ainda, que quem entrar nesta dinâmica a multiplicará, pois na medida em que seja hoje o salvador, amanhã encarnará a vítima e, por fim, tornar-se-á perseguidor.

Ressalta-se que o presente trabalho não parte da compreensão de vítima no sentido dado pela ONU, pois não se entrará no mérito da legislação penal. Tampouco se refere às vítimas que demonstraram traumas (com sintomas associados ao transtorno do estresse pós-traumático). Como afirmam Kellermann e Hudgins (2010), casos de traumas demandam cuidados especiais na utilização do psicodrama e na inversão de papéis, para evitar uma possível retraumatização. O sentido de vitimização aqui abordado se assemelha mais às dinâmicas descritas por Karpman (2019) e Barreto (2008), nas quais a vítima faz parte de um modus operandi contextualizado por uma relação triangular, porém com algumas diferenças. Karpmam (2019) apresenta a triangulação com ênfase no drama familiar e em traumas passados, enquanto a conceituação aqui proposta de SVV pretende apreender a triangulação frente ao manejo de desafios, com ênfase no presente e futuro. 
Karpman (2019) e Barreto (2008) utilizam o termo perseguidor (na triangulação com salvador e vítima), enquanto na SVV optou-se pelo termo algoz para a denominação do vértice lesionador, por sugerir uma concepção atribuída de maldade genérica, mais apropriada para o que se observou na experiência de trabalho relatada.

\section{Teoria socionômica}

A socionomia, principal fundamentação teórico-metodológica deste trabalho, considera os "papéis" do indivíduo como os aspectos tangíveis a partir dos quais este opera sua vida real - que contém aspectos privados, sociais e culturais —, sendo determinante para uma comunicação adequada, formação e adaptação da personalidade e desenvolvimento do Eu social (Moreno, 2002). Como parâmetro de relação sadia e elemento essencial para a eficácia de qualquer terapia, temos o fator tele - que possibilita a percepção íntima e mútua dos indivíduos com base no sentimento e conhecimento da situação real das outras pessoas, além de favorecer a coesão dos grupos. A tele é imprescindível para a ocorrência do encontro, associado ao estar junto, ao contato, ao conhecer, e abrange não apenas relações amáveis, mas também hostis (Moreno, 1999). A transferência, por outro lado, é uma forma de percepção equivocada do indivíduo, já que distorce o outro com projeções do mundo interno do primeiro, além de gerar confusão da relação atual com conflitos e experiências do passado. Apesar de compreendida como patológica, a transferência pode oferecer dicas para a viabilização da tele na busca de uma relação saudável e um processo de cura (Santos \& Vasconcellos, 2016). Bustos (1980) descreveu um modelo de relação transferencial através da dinâmica que nomeou de complementar interno patológico (CIP). Neste, o desenvolvimento de um papel-chave do sujeito vivido de maneira muito conflituosa pode gerar sua reprodução em outras relações, comprometendo outros papéis, por haver uma influência maior de comportamentos e emoções ligadas ao passado (interno patológico) do que dos vínculos reais atuais. Uma relação baseada no CIP pode se desenvolver de três formas, as quais se exemplificam aqui a partir do drama do término inesperado do serviço de atendimento psicológico na comunidade: (1) com a configuração do papel e contrapapel do usuário do serviço de atendimento à comunidade que se sente "abandonado/vítima" com o técnico/psicólogo que se sente "abandonador/algoz" (relação patológica direta); ou (2) do usuário "abandonado/vítima" com o técnico "onipotente/salvador" que tentará não abandoná-lo nunca (relação patológica reativa); ou ainda (3) do técnico que percebe o drama histórico relacionado à função vitimizada e ao abandono, mas que busca, com a comunidade, uma alternativa criativa para transformação do conflito e desvencilhamento do CIP, por exemplo, com a ritualização do término do serviço, incluindo a vivência da tristeza pelos limites da intervenção oferecida, mas também com a comemoração pelos aprendizados e legados adquiridos com essa experiência (relação corretiva).

\section{Objetivos}

O objetivo geral desta pesquisa é compreender como as pessoas lidam, entendem, reagem e se responsabilizam frente ao manejo dos desafios da vida no seu dia a dia. Os objetivos específicos são: (1) descrever e discriminar padrões de conduta iatrogênicos que dificultam a prática do manejo de desafios e geram sofrimento, daqueles que, pelo contrário, são terapêuticos, viabilizam participação e geram superação; (2) demonstrar que a teoria de papéis da socionomia, com sua ênfase no aspecto relacional e em técnicas de ação, auxilia na transição do manejo patológico para o terapêutico dos desafios.

\section{METODOLOGIA}

Trata-se de uma pesquisa qualitativa, um relato de experiência, na qual o autor — para identificar e caracterizar uma proposta teórica - desempenhou o papel de psicólogo/técnico em um programa governamental, como observadorparticipante, inserido no eixo governo/incubadora/técnico/comunidade/família.

Foram utilizados basicamente dois critérios de registro para a coleta de dados: o primeiro, referente ao vetor 1 (técnico/ comunidade/família), é embasado essencialmente pela sociatria — nas intervenções com grupos efetuados em território 
— e pelas múltiplas possibilidades que ela oferece, como os instrumentos (diretor, egos-auxiliares, protagonista, cenário e plateia), contextos (social, grupal e psicodramático), etapas (aquecimento, dramatização e compartilhamento) e técnicas básicas (duplo, espelho e inversão de papéis). Como não houve intervenção sociátrica no vetor 2 (técnico/incubadora/ governo), pois não era atribuição do técnico, utilizou-se outro critério para o registro, embasado primordialmente na sociodinâmica dos diferentes papéis envolvidos. Esse recurso, no caso, caracterizou-se pela identificação de comportamentos espontâneos dos envolvidos - — não a espontaneidade criativa, elemento perseguido pelo psicodrama, mas a espontaneidade por si, que emerge e revela.

No vetor 1, utiliza-se o que Merengué (2006) chama de dramatização investigativa (caracterizada por intervenção direta e técnica) e, no vetor 2 , o que aqui foi nomeado de espontaneidade investigativa (caracterizada por uma observação livre e intuitiva).

\section{RESULTADOS}

Este capítulo está dividido pelo olhar do técnico direcionado a dois vetores: 1) a comunidade, que usufruiu do serviço; 2) a incubadora/governo, que deu suporte ao serviço.

\section{Olhar para o vetor técnico/comunidade/família}

Herdou-se da técnica antecessora espaços para o programa criados na comunidade: Unidade Básica de Saúde (UBS), Igreja Católica, associação comunitária, duas escolas; e a casa de seu João e dona Antônia (nomes fictícios), um casal que cedia o espaço da laje de sua casa.

Com esses espaços de referência, deu-se início (ou continuação) a uma série de grupos para lidar com os desafios dos moradores da comunidade: grupo de agentes comunitários de saúde (ACS), de orientação de pais, de adolescentes em parceria com profissionais da UBS, três grupos abertos situados em locais distintos (para qualquer um da comunidade que necessitasse dos serviços do programa), bem como grupos de professores nas duas escolas citadas.

Cada grupo, desenvolvido em parcerias com a comunidade, constituiu-se levando em conta critérios que facilitassem o acesso da população ao programa, sendo estes: a frequência - os grupos principais eram semanais, para estimular seu caráter processual; a localização - em regiões diversificadas; o perfil - havia grupos específicos para alguns perfis populacionais, fosse pelo seu caráter multiplicador (ACS, professores e pais), fosse pela sua particularidade (adolescentes); e a divulgação - cada parceria se responsabilizava por uma parcela da divulgação do serviço.

Considerou-se que o esforço do técnico para facilitar o acesso dos membros da comunidade ao programa, garantindo-lhes o direito ao serviço, deveria ser complementado pelo compromisso desses membros, pelo esforço conjunto para superar eventuais obstáculos pessoais que os impedissem de acessar o programa. Ou seja, compreendeu-se que a responsabilidade pelo usufruto e acesso ao programa era compartilhada entre técnico e comunidade. Essa estratégia foi definida pelo psicólogo/técnico/autor deste texto para não reproduzir uma sensação, relatada por outros técnicos, de "carregar mais do que se dá conta". Alguns parâmetros foram estabelecidos para operacionalizar essa corresponsabilização: desafios e soluções não deveriam ser projetados a partir de um desejo do técnico, mas a partir de uma demanda ou desejo da comunidade. O técnico não estava lá para fazer tudo o que precisava ser feito, mas sim tudo o que era possível fazer. Colocava-se à disposição para desenvolver potenciais e iniciativas que já estivessem efetivamente na comunidade.

Os grupos abertos eram os que mais desafiavam a habilidade de lidar com o inesperado. A diversidade revelava surpresas a cada encontro: lidar com usuário de drogas na família, divórcio, filhos com dificuldades na escola ou problemas de comportamento, desacordo entre familiares, solidão etc. No caso de pais que procurassem atendimento para seus filhos, por exemplo, estes também eram requisitados a participar do atendimento. O desenvolvimento das relações familiares e sociais em bom acordo com as escolhas individuais era priorizado. A seguir, uma cena marcante de cada grupo que representa esse esforço, do ponto de vista do autor desta produção escrita. 
- Exemplo 1 - Grupo de Orientação de Pais: Numa queixa, uma mãe não sabia o que fazer com o filho, agressivo e desafiador. Em cena dramatizada, ela chegou em casa do trabalho e, vendo a louça suja, rompeu em desespero gritando com o filho sobre a bagunça. A mãe se deu conta de sua agressividade e percebeu que sua reação, que incrementava uma sensação de amargor e solidão, tinha a ver com suas frustrações do trabalho, e não com o filho. Comentários: Identificou-se um ciclo transferencial de agressividade e culpabilização, gerando a busca de um novo modelo de conduta com parâmetros mais positivos.

- Exemplo 2 - Grupo aberto da casa da dona Antônia: Em cena psicodramática, uma moradora reclamou da demora do atendimento na UBS, onde inclusive se passava sede, pois nem bebedouro tinha, gerando sentimentos de "impotência" e "raiva" nos membros do grupo, direcionados ao gerente da unidade. Sugeriu-se que alguém se colocasse no papel desse gerente (o único que, segundo o grupo, poderia resolver o problema). Uma moradora, assumindo o papel de gerente, falou: "Tenho mil problemas pra resolver, mas vocês têm razão! Era pra ter um bebedouro aqui, sim!". Alguém sugeriu fazer um abaixo-assinado, como "forma da gente mostrar que isso tem que ser resolvido com prioridade" (SIC). Algumas semanas depois, o abaixo-assinado, com 74 assinaturas, chegou ao gerente da unidade, que, mobilizado, levou a questão para a reunião com outros gerentes de unidade e descobriu que era um problema generalizado no município. Uma licitação foi desenvolvida para atender à demanda. Antes, porém, de um desfecho via licitação, um bebedouro antigo foi encontrado e consertado, resolvendo o problema.

Comentários: De início, o poder parecia todo concentrado no gerente da UBS, descrito como o "culpado" ("algoz" da situação, por permitir que a comunidade — "vítima” - quando necessitasse de tratamento, ainda passasse sede). A cena sofreu um revés quando um possível ponto de vista dele foi vislumbrado. Bastante ocupado e preocupado em administrar uma UBS já cheia de desafios, o médico ainda teve que aguentar (vítima?) membros da comunidade agressivos (algozes?) exigindo a resolução de um problema difícil de resolver (salvador?). O vislumbre da perspectiva do gerente, no entanto, fez com que ele fosse visto com mais humanidade e empatia, de modo a dissolver qualquer agressividade. Houve uma realocação de responsabilidades, com a comunidade assumindo parte do poder de transformação da situação (cidadania?). Chegou-se a sugerir que o psicólogo redigisse o abaixo-assinado, mas este topou ajudar como auxiliar, não como autor principal (esquiva do papel de salvador?), devolvendo aos membros da comunidade a autoria que lhes cabia. Note-se o efeito-cidadão em cadeia que ocorreu, na medida em que o abaixo-assinado gerou uma mobilização capaz de iniciar um processo de resolução para o problema em todo o município.

- Exemplo 3 - Grupo aberto da Associação Comunitária: Uma cena significativa ocorrida nesse grupo foi motivada pela insatisfação das mães com o desempenho escolar dos filhos, que apresentavam dificuldades de aprendizado e que, devido à lei de progressão continuada ${ }^{1}$, ficavam defasados em seus estudos. Usando o princípio da inversão de papéis, alguns professores representaram a diretora, que, ao ouvir reclamações agressivas, respondeu também com agressividade. As mães concordaram de imediato com a necessidade de abordar a questão de outra forma, tanto com a diretora quanto com o problema. Passadas duas semanas, essas mães, em parceria com a associação comunitária, montaram, por sua própria conta, dois grupos de reforço escolar na garagem de um morador local. Comentários: O reempoderamento do grupo, que inicialmente estava depositando a culpa e o poder de resolução do problema na diretora, foi imediato. Todos os que foram diretamente responsáveis pela criação do grupo de reforço estavam presentes na sessão descrita acima — o presidente da associação, que viabilizou a garagem como sala de aula, e uma jovem que se tornou a professora dos grupos de reforço.

- Exemplo 4 - Grupo de professores: Num jogo dramático constituído por uma história concebida por professores e coordenação, surgiu uma personagem-professora que não media esforços para ajudar um aluno pobre e com

1. Lei de Diretrizes e Bases da Educação (lei 9.394, de 1996), artigo 32. 
dificuldade de aprendizagem, oferecendo-lhe inclusive seus finais de semana para ajudá-lo. O fim da história fictícia é feliz, de superação por parte do aluno. No entanto, a dinâmica do jogo revelou que a diretora assumia recorrentemente o ônus de finalizar as histórias criadas - uma responsabilidade que ninguém mais queria assumir. Logo, identificou-se que na vida real a diretora era semelhante à personagem-professora, pois no dia a dia não media esforços para resolver os problemas dos professores.

Comentários: Houve, nesse episódio, a identificação da idealização do sacrifício sem medidas pelo outro (papel de salvador). Curiosamente, o sacrifício irrestrito na vida real da diretora (com consequências em sua vida pessoal) reforçou uma consequência negativa: o contrapapel de professores que acabavam não se responsabilizando o suficiente (com atrasos, por exemplo), pois sabiam que alguém lhes cobriria. Uma provável segunda consequência, relataram alguns, foi a sensação da falta de conquistas na vida profissional.

- Exemplo 5 - Grupo de Agentes Comunitários de Saúde (ACS): Foram recorrentes as cenas com ACS envolvendo o tema de suas atribuições e os limites de seu papel, fosse em situações nas quais eram comparados e um ACS era considerado melhor quando entrava nas casas para tomar café (apesar de terem muitas tarefas pra cumprir e pouco tempo); fosse em situações em que eram cobrados como se devessem fornecer camisinha para alguém que vinha pedi-la em sua casa à meia noite, ou mesmo em situações em que eram acusados de abandono da comunidade, caso não estivessem disponíveis permanentemente, pois "poderia haver uma emergência" (SIC). Comentários: Algo marcante nesse grupo foi que os ACS começaram a se cuidar, oficializar procedimentos, definir estratégias e se fortalecer enquanto grupo. Estes compreenderam a importância de estabelecer limites (esquivando-se de um lugar de salvador onipotente) e passaram a se reunir de portas fechadas com placa de "não interromper".

- Exemplo 6 - Grupo de adolescentes na UBS: Uma cena significativa desse grupo, que ajudou no vínculo dos participantes com o programa, referiu-se à dramatização de uma adolescente discutindo com sua mãe sobre ter ou não camisinha em sua bolsa. Na discussão, os adolescentes experimentaram o papel da filha e da mãe. Muitos elogiaram a firmeza que a filha foi adquirindo, com articulação de argumentos, que na cena transformaram uma imposição da mãe de tirar a camisinha da bolsa em um treino de negociação entre mãe e filha.

Comentários: $\mathrm{O}$ ponto alto do grupo, segundo vários adolescentes, foi o exercício de expressar opinião em grupo e negociar (características do papel de cidadão). Alguns disseram que, mesmo quando o desfecho do conflito não foi em seu favor, seja na dramatização ou na vida real, só o fato de poder se expressar ou se sentir compreendido já validava a experiência.

- Exemplo 7 - Grupo aberto da Igreja Católica: Este foi um grupo que, assim como os outros grupos abertos, com o tempo começou a receber frequentadores assíduos - que foram os que mais sentiram a notícia de que haveria o término do atendimento psicológico na região. Nele, conversamos a respeito da dificuldade, porém da importância, da despedida. Alguns falaram de entes queridos que perderam e o que haviam aprendido com eles. Também conversamos sobre o que cada um deixava e levava do grupo

Comentários: A ritualização do término e da despedida foi considerada prioritária neste e em outros grupos, pois se compreendeu que trabalhar seu significado poderia representar a diferença entre os envolvidos sentirem-se vítimas de "mais um evento danoso" gerado pelo governo e pela vida, ou sentirem-se diante da oportunidade do aprendizado de que tudo pode ter fim, mas que é possível fazer uma reflexão construtiva sobre a experiência.

\section{Olhar para o vetor técnico/incubadora/governo}

Desde que foi proposta, a descrição da experiência do trabalho na comunidade, bem como das instâncias que lhe davam suporte, deixou claro que a reação predominantemente vitimizada dos técnicos, quando anunciado o término do 
programa, foi coerente com a postura da prestação do serviço como um todo. Isso porque os exemplos que marcaram o autor desta produção escrita, para representar sua experiência com o suporte do trabalho, revelaram uma característica cultural focada nas figuras de vítima, salvador e algoz, como veremos a seguir:

- Exemplo 8: A remuneração dos técnicos era realizada, recorrentemente, com pelo menos um mês de atraso. Com a troca de governo após as eleições, o governo substituto, para averiguação dos gastos públicos, paralisou os salários dos envolvidos no programa por tempo indeterminado. Isso durou três meses, gerando problemas financeiros para alguns técnicos, que reclamaram com resignação: "É assim mesmo, fazer o quê?" (SIC).

Comentários: O desemparelhamento temporal entre trabalhar e ser remunerado deu uma sensação de desequilíbrio entre direitos e deveres. Afinal, o técnico tinha o dever de honrar os compromissos (e prazos) assumidos perante a comunidade, sob pena de manchar sua imagem e a do governo (o qual representava). Ao mesmo tempo, seu direito de receber em data predeterminada não estava assegurado. Além disso, o atraso no recebimento poderia gerar dívidas e juros no banco, mas o pagamento atrasado não sofria qualquer reajuste.

- Exemplo 9: Os técnicos foram incumbidos de preencher um grande número de cadastros extensos com prazo de entrega muito curto. Havia mudanças constantes nas orientações sobre o preenchimento do cadastro e muitos técnicos passaram a considerar que era "melhor" fazê-lo de última hora, para não correr o risco de ter de refazê-lo depois.

Comentários: Houve desconsideração de que o técnico tivesse outras atribuições preexistentes ao tal cadastro. A consequência relatada pelos técnicos foi a sensação de desconsideração, estresse, bem como de insatisfação e culpa com seu próprio desempenho.

- Exemplo 10: A necessidade de relatórios quantitativos e qualitativos para justificar a relevância do trabalho, somada ao medo deste ser interrompido, gerou na incubadora uma resposta de valorizar, nos registros, traços superlativos quanto aos feitos do técnico, seguida de pressão para que os técnicos desempenhassem feitos semelhantes ao descrito.

Comentários: Tanto essa pressão quanto a desconsideração apontada no item anterior sugerem que havia uma desconstrução de limites saudáveis para a performance do técnico, gerando nele a sensação crônica de que "nunca é o suficiente" (SIC).

- Exemplo 11: Três funcionários do setor governamental parceiro do programa deveriam se reunir regularmente com o técnico/autor desta produção, como um apoio ao qual este poderia recorrer caso precisasse. Esses funcionários foram frequentemente acessíveis por telefone, mas dificilmente cumpriram alguma promessa — faltaram a várias reuniões e invariavelmente chegaram atrasados nos compromissos marcados. Eles mostraram, respectivamente, as seguintes posturas para com seu trabalho (sendo destacado entre parênteses o tempo de serviço de cada um no respectivo setor governamental): 1 - Esperançoso na realização de seu trabalho (três anos); 2 - Negativo, porém sorridente (cinco anos); 3 - Negativo, desesperançoso e cansado (dez anos), a ponto de desafiar o mais novo no serviço: "quero ver por quanto tempo que você vai continuar assim otimista" (SIC).

Comentários: Há uma clara correlação entre tempo de serviço, pessimismo e cansaço crescente dos funcionários descritos. O mais antigo, aliás, era também quem mais falhava em profissionalismo e pontualidade, e ainda o que mais parecia exaurido. Este bem explicou o seu processo de mudança ao longo dos anos: "a cada troca de governo tudo muda, e dá a sensação de que todo o trabalho feito ali caiu por terra (foi em vão)” (SIC).

- Exemplo 12: Durante as eleições, técnicos foram pressionados a aumentar seus resultados (quantitativos e qualitativos) e, mesmo após a vitória da oposição do governo, houve comunicação de possível continuidade do trabalho. Porém, logo vieram informações desencontradas sobre o término. A data do último dia de trabalho 
mudou cinco vezes desde quando estabelecida pela primeira vez, até sua efetivação, chegando a haver alterações no próprio dia do suposto término. Técnicos relataram impotência, estresse e frustração, pois, além de perder seus empregos, não poderiam cumprir promessas feitas à comunidade. Alguns deles, sentindo-se culpados e para compensar sua sensação de "abandono", optaram por trabalhar na comunidade voluntariamente após o término oficial do serviço, enquanto outros relataram, por vergonha ou dificuldade, terem sumido sem se despedir.

Comentários: Informações desencontradas sobre a finalização desgastaram os técnicos e dificultaram a elaboração de um processo mais cuidadoso de finalização junto à comunidade com a qual se desenvolvia o trabalho. Alguns técnicos chegaram a relatar a sensação (de forma semelhante ao Exemplo 11) de que todo o seu trabalho havia sido feito em vão.

- Exemplo 13: Em reunião, representantes do novo governo alegaram que o programa continuaria na cidade, mas mudariam as regiões abarcadas, pois houvera uma mudança de parâmetros na avaliação de vulnerabilidade social. Sendo assim, os locais que não eram mais considerados de altíssima vulnerabilidade social perderam o programa. Comentários: A justificativa alegada para a finalização do programa em determinadas áreas parece não ter levado em conta a opinião dos prestadores de serviço, tampouco se mostrou calcada em conquistas adquiridas nos territórios atendidos. Os argumentos utilizados se apoiavam na mudança de critério de vulnerabilidade, ou seja, numa avaliação de que "o outro lugar precisava mais". Informalmente, os prestadores de serviço especularam que os "verdadeiros" motivos das mudanças estariam relacionados ao apadrinhamento político. Por fim, técnicos e membros da comunidade tenderam a compreender o trabalho como interrompido, com sensação generalizada de perda e abandono, ao invés da sensação positiva de realização de um trabalho finalizado, que gerou conquistas.

\section{DISCUSSÃO}

As cenas destacadas pelo técnico/autor desta produção, no trabalho realizado com a comunidade, tiveram inicialmente, em sua maioria, um tom de reclamação e culpabilização: numa ponta da relação, a comunidade reclamava do atendimento na UBS e, na outra, profissionais da unidade se queixavam da comunidade; pais também reclamavam dos filhos e dos professores/diretoria etc. Um dos recursos socionômicos utilizados, particularmente eficaz para não reproduzir um CIP com característica vitimizada, foi o princípio da inversão de papéis. Nessa experimentação do "como se" do seu papel complementar, trabalhou-se com a implicação de quem expõe o problema (sua parcela de corresponsabilidade) e a busca de compreensão do contrapapel da relação. Com isso, deixou-se de perceber o outro como alguém (super)potente (culpado), fundamentalmente do bem (salvador), do mal (algoz) ou ainda (im)potente (vítima). Nas intervenções exemplificadas, através da dramatização e por variados jogos com papéis, observou-se que: relações transferenciais podem colocar indivíduos sem querer na posição de algozes (Exemplo 1); remover o outro da posição de algoz gera empoderamento (Exemplos 2 e 3); manter-se no lugar de salvador dificulta ao outro desenvolver senso de responsabilidade e realização (Exemplo 4); começar a impor limites pode iniciar uma esquiva ao lugar de salvador (Exemplo 5); aprender a se expressar, ouvir, negociar num conflito pode gerar satisfação e empoderamento, independentemente do resultado (Exemplo 6); estratégias como a ritualização podem ser uma forma de lidar com perdas sem posicionar-se no lugar de vítima (Exemplo 7). Logo, a busca por culpados transformou-se na busca de soluções pautadas em viabilidade, equilíbrio entre direitos e deveres, limites e potências.

Dentro do programa, técnicos, membros da incubadora e do governo também reclamaram de performances entre si. Os técnicos encontraram-se numa dinâmica com direitos negligenciados - como não ter data para receber seu salário (Exemplo 8) e com visão de responsabilidades atribuídas de forma desproporcional (Exemplos 9 e 10), reforçando neles a sensação de ocuparem uma posição de vítima impotente e sofredora ou de salvador onipotente que não necessitaria de direitos, gerando frustração e até exclusão social. A sensação de impotência e insatisfação de servidores de outras instâncias do setor de saúde permitiu a observação do quanto estava arraigada uma cultura vitimizada dentro do próprio governo (Exemplo 11), reforçando uma percepção de "sempre foi assim e sempre será". A falta de preparação, bem como 
de repertório para manejo do término do programa, gerou angústia e sensação de abandono nos técnicos, elevou o tom das reclamações e culpabilizações em relação aos desafios da comunidade (Exemplo 12) e ainda os excluiu de participação no direcionamento do programa no qual eram agentes (Exemplo 13). O próprio técnico autor deste texto não esteve isento de se sentir lesado, o que se vê pelo teor dos registros envolvendo sua equipe de suporte de trabalho. Moreno (1994) diz que a pressão exercida por papéis secretos em papéis oficiais pode causar ansiedade. No caso descrito, o papel de técnico tem a atribuição oficial de promoção da característica cidadã, mas com uma dinâmica não oficial do próprio programa governamental fomentando uma cultura de característica vitimizada.

O conceito de sistema foi descrito por Moreno como uma força interna que busca sua auto-organização (Marra \& Costa, 2004). Já sistema vincular enfatiza a natureza dos padrões de relação entre indivíduos e grupos, que inclui pontas relacionais e características vinculares específicas (e nas quais o indivíduo pode também transitar por duas ou mais pontas do mesmo sistema). Com isso, propõe-se a expressão Sistema Vincular Vitimizado para conceituar a sociodinâmica que envolve a relação entre vítima, algoz e salvador. Já para conceituar o padrão de desempenho de papéis afinado com a função oficial do técnico e com o objetivo do programa, propõe-se a expressão Sistema Vincular Cidadão (ver Fig. 1).

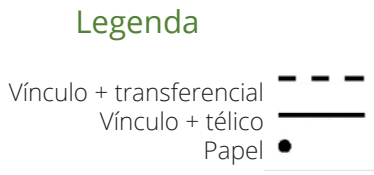

Cidadão (SVC)

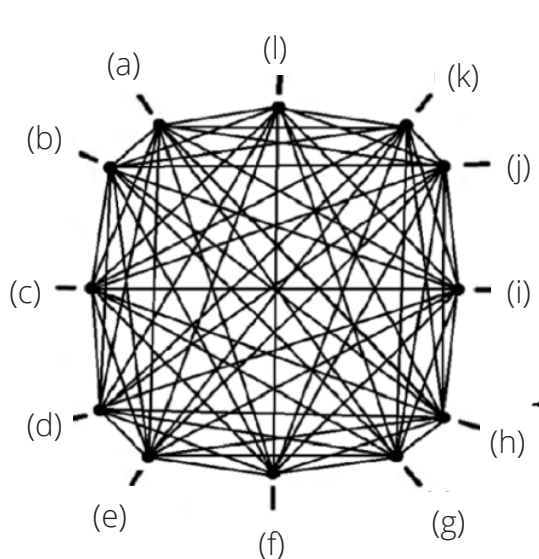

Vitimizado (SVV)

onipotente

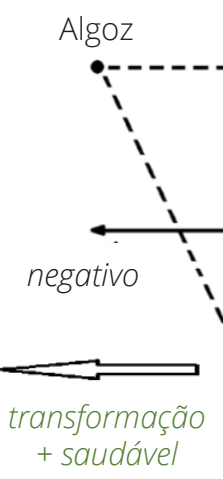

+ saudável

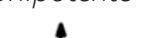

Salvador

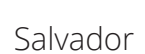

Salvador

impotente
Martirizado (SVM)

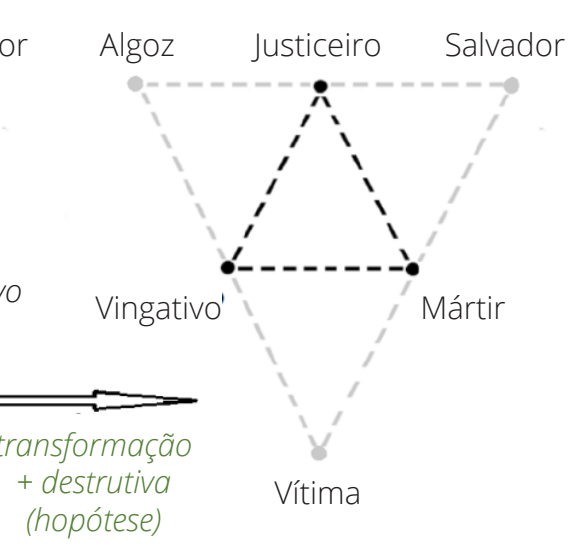

Figura 1 - Infográfico Sistemas Vinculares

O sujeito que se relaciona pelo SVV opera com um parâmetro de responsabilidade transferencial e desequilibrado, no sentido de muitos direitos (que inclui a intenção reparatória pela desgraça vivida) e pouco ou nenhum dever atribuído à considerada vítima. Deveres e culpas são investidos nos complementares onipotentes de valor positivo (salvador) e negativo (algoz). Já no SVC, a responsabilidade atribuída é de característica télica e com o poder de resolução compartilhado com o outro, o coletivo e o universo, através de vínculos modulados por critérios de viabilidade, negociação e escolha como instrumentos de transformação.

A identificação do SVV (por suas sensações, percepções etc.) pode ser útil como diagnóstico situacional e indica uma consequência potencialmente insatisfatória, além de sugerir uma demanda de intervenção no sentido de exercitar o SVC (ver Tabela 1).

Nota-se que a temática envolvendo a vitimização e a cidadania é profunda e ampla, e que quanto mais nela nos debruçamos, mais elementos parecem necessitar de investigação. Nesse sentido, talvez essa produção teórica gere muitas perguntas, possíveis objetos de futuros estudos. Quais são os principais fatores que mantêm o indivíduo em SVV ou SVC? Seriam esses sistemas etapas diferentes de um mesmo processo evolutivo? Talvez a maior contribuição deste trabalho esteja na descrição e no 
Tabela 1 - Caracterização do SVC e do SVV

\begin{tabular}{ccc}
\hline & $\begin{array}{c}\text { Sistema Vincular Cidadão } \\
\text { (SVC) }\end{array}$ & $\begin{array}{c}\text { Sistema Vincular Vitimizado } \\
\text { (SVV) }\end{array}$ \\
\hline Compreensão & $\begin{array}{c}\text { Poder distribuído por corresponsabilidade sob a } \\
\text { forma de direitos/deveres. }\end{array}$ & $\begin{array}{c}\text { Poder concentrado em alguns indivíduos } \\
\text { ("culpabilização") e de característica maniqueísta. }\end{array}$ \\
\hline Percepção & Predominantemente télica. & Predominantemente transferencial. \\
\hline Ação & $\begin{array}{c}\text { Proativa, resiliente, negociadora, remodeladora, com } \\
\text { ênfase na eficácia e na resolução dos problemas. }\end{array}$ & $\begin{array}{c}\text { Reativa, resignada, autoritária, circunscrita, com } \\
\text { ênfase no desabafo e na busca de bodes expiatórios. }\end{array}$ \\
\hline Comunicação & Acessível e de troca. & Distante e unilateral. \\
\hline Sensação & $\begin{array}{c}\text { Proximidade, segurança, esperança, } \\
\text { empoderamento, esforço, renovação, confiança, } \\
\text { realização, aprendizado, suficiência, satisfação. }\end{array}$ & $\begin{array}{c}\text { Isolamento, vulnerabilidade, pessimismo, } \\
\text { incia, estresse, exaustão, angústia, culpa, } \\
\text { insatisfação, insuficiência, decepção. }\end{array}$ \\
\hline Referencial conceitual & Justiça, responsabilidade compartilhada. & Injustiça, culpa concentrada.
\end{tabular}

detalhamento dessas duas sociodinâmicas (SVC e SVV), mas, não menos importante, e de muita utilidade, é a demonstração de que se colocar no lugar do outro favorece um deslocamento do SVV para o SVC.

Para estudos futuros, hipotetiza-se que a cristalização no SVV possa eventualmente derivar em outro sistema vincular que não apenas gere insatisfação, mas tenha nuances mais claramente destrutivas, aqui nomeado de Sistema Vincular Martirizado (SVM) (ver Figura 1). Nesse sistema, também triangular, entre o lugar de salvador e vítima estaria o vértice do mártir (com sensação de injustiça e impulso autodestrutivo); entre a vítima e o algoz estaria o vingativo (com sensação de mágoa e desejo heterodestrutivo); e entre algoz e salvador, o justiceiro (com sensação de raiva e impulso por justiça vingativa).

\section{CONSIDERAÇÕES FINAIS}

As sociodinâmicas propostas nesta produção escrita — SVV e SVC — podem ser consideradas sistemas de compreensão da realidade que têm como gatilho ou se tornam manifestos quando os indivíduos envolvidos se deparam com situações de desafios (crônicos, novos e/ou inesperados). O SVV se apresenta com característica, de certa forma, mais simplificada, pois é baseado em conclusões que seguem um parâmetro binário de potência (culpado/inocente) e valor (bem/mal). Neste, o foco parece maior em reafirmar conclusões preestabelecidas, ou seja, de atribuição maior de poder ao algoz e ao salvador, do dano sofrido pela vítima etc. O SVC se apresenta com compreensão mais voltada para o processo do desafio, em que potências e valores vão sendo descobertos e coconstruídos sem uma preocupação com conclusões definitivas, mas sim com um foco no seu manejo e superação.

Com seus padrões específicos de sensação, percepção, interação e responsabilização, o SVV se mostrou propenso a reproduzir uma dinâmica de exclusão social, enquanto o SVC apresentou-se como uma ferramenta para promover a inclusão social.

Vale ressaltar que o SVV foi identificado na sociedade como um todo e não como um fenômeno de determinada região ou classe social, já que ocorreu na periferia, na incubadora (situada em área nobre) e no governo. Na periferia, o SVV se mostrou passível de transformação para SVC a partir da metodologia socionômica, enquanto na incubadora e no governo isso não pôde ser avaliado, pois não houve uma intervenção nesse sentido.

Sugere-se que novos estudos possam identificar os SVV e/ou SVC como possíveis diagnósticos situacionais em outros contextos, assim como a caracterização de outros sistemas vinculares (como o SVM), ou ainda outras formas de intervenção nos mesmos.

\section{DISPONIBILIDADE DE DADOS DE PESQUISA}

Todos os dados foram gerados ou apresentados neste estudo. 


\section{FINANCIAMENTO}

Não se aplica.

\section{AGRADECIMENTOS}

Agradeço à Rosa Cukier, ao Alexandre Saadeh e a todas as pessoas que contribuíram, direta e indiretamente, para a realização deste trabalho.

\section{REFERÊNCIAS}

Barreto, A. P. (2008). Terapia Comunitária: Passo a Passo. Gráfica LCR.

Bustos, D. M. (1980). O Psicodrama: Aplicação da Técnica Psicodramática. Summus.

Camargo, E. P. (2017). Inclusão Social, Educação Inclusiva e Educação Especial: Enlaces e Desenlaces. Ciência E̋ Educação, 23(1), 1-6. https://doi.org/10.1590/1516-731320170010001

Fichtner, B. (2017). Exclusão social e inclusão social: À procura de uma alternativa emancipatória nas ciências humanas. Educativa, 20(2), 447-468. https://doi.org/10.18224/educ.v20i2.6244

Gulassa, D. C. R. (2018). O acompanhamento terapêutico como multiplicador de egos auxiliares. Revista Brasileira de Psicodrama, 26(1), 76-85. https://doi.org/10.15329/2318-0498.20180003

Karpman, S. (2019). Script Drama Analysis II. International Journal of Transactional Analysis Research E Practice, 10(1), 21-39. https://doi.org/10.15329/2318-0498.20180003

Kellermann P. F. (2010). Aspectos terapêuticos do psicodrama com traumatizados. In Kellermann P. F., \& Hudgins, M. K. (2010). Psicodrama do Trauma. Ágora.

Marra, M. M., \& Costa, L. (2004). A pesquisa-ação e o sociodrama: Uma conexão possível? Revista Brasileira de Psicodrama, 12(1), 99-116.

Mello, A. C., \& Lira, L. R. (2019). Vitimologia no direito penal: Importância da vítima no delito. https://ambitojuridico. com.br/cadernos/direito-penal/vitimologia-no-direito-penal-importancia-da-vitima-no-delito/

Merengué, D. (2006). Psicodrama e investigação científica. In A. Monteiro, D. Merengué, \& Valéria Brito. Pesquisa Qualitativa e Psicodrama. Ágora.

Moreno, J. L. (1994). Quem Sobreviverá Vol. II. Dimensão.

Moreno, J. L. (1999). Psicoterapia de Grupo e Psicodrama. Livro Pleno.

Moreno, J. L. (2002). Psicodrama. Cultrix.

Morotti, C. (2015). Vitimização primária, secundária e terciária. https://morotti.jusbrasil.com.br/artigos/210224182/ vitimizacao-primaria-secundaria-e-terciaria

Porto, D. (2018). Mononormatividade, intimidade e cidadania. Revista Direito GV, 14(2), 654-681. https://doi. org/10.1590/2317-6172201825

Santos, F., \& Vasconcelos T. T. (2016). Leitura conceitual sobre o fenômeno da transferência na cena psicodramática. Revista Brasileira de Psicodrama, 24(1), 7-15. https://revbraspsicodrama.org.br/rbp/article/view/50/56

Yalon, Y. D., \& Leszcz, M. (2006). Psicoterapia de grupo: Teoria e prática. Artmed.

Zampieri, M. A. J. (2005). Terapia de Rua e Cidadania. In H. Fleury \& M. M. Marra (Org.), Intervençôes Grupais nos Direitos Humanos. Ágora. 